\title{
Synthesis and Characterization of a Novel Heteropoly Acid/Hydrogel Composite
}

\author{
Junjie ZHU ${ }^{1 *}$, Takehiko GOTOH ${ }^{1}$, Satoshi NAKAI ${ }^{1}$, and Masahiro SADAKANE ${ }^{2}$ \\ ${ }^{1}$ Department of Chemical Engineering, Graduate School of Engineering, Hiroshima University, 1-4-1, Kagamiyama, Higashi- \\ Hiroshima 739-8527, Japan \\ ${ }^{2}$ Department of Applied Chemistry, Graduate School of Engineering, Hiroshima University, 1-4-1, Kagamiyama, Higashi-Hiroshima \\ 739-8527, Japan
}

\begin{abstract}
Catalysis by Heteropoly acids (HPAs) and polyoxometalates (POMs) having a higher demand worldwide, as it can be designed to accelerate complex reactions and be more environmentally friendly. However, recycling of water-soluble solid catalysts remains a problem. The synthesis of a recyclable composite with catalytic properties is the key to better use of HPAs and POMs. Many researches have mentioned the method of synthesis by immersing a porous carrier in a supported solution. However, the catalytic stabilities of the previously studied composites after multiple uses have rarely been mentioned. In this research, a novel idea is proposed to synthesize a heteropoly acid supported composite. A complex hydrogel with catalytic properties was synthesized by mixing an anionic monomer with a heteropoly acid. The heteropoly acid particles were inserted inside the hydrogel by the interaction forces between the anions. Thus, preventing the water-soluble heteropoly acid from being lost during the catalytic reaction. The complex hydrogel is consisted of the anionic monomer 2-acrylamide-2methylpropanesulfonic acid (AMPS) as a carrier, $N, N^{\prime}$-Methylenebisacrylamide (MBAA) as crosslinkers and the typical Keggin-type HPA: $\mathrm{H}_{3} \mathrm{PW}_{12} \mathrm{O}_{40}$. At last, a composite with $\left(\mathrm{NH}_{4}\right)_{3} \mathrm{PW}_{12} \mathrm{O}_{40}$ particles was synthesized.
\end{abstract}

\section{Introduction}

Homogeneous catalysts usually bring excellent yield of production while causing environmental pollution, equipment corrosion and hard catalyst separation, which limit the extensive industrial application process of them.

Thus, the construction of high selective, active, stable, easily recyclable heterogeneous catalysts is a challenging goal of liquid phase oxidation catalysis (Cavani et al., 2009; Clerici and Kholdeeva, 2013; Duprez and Kholdeeva, 2014).

Polyoxometalates (POMs) are discrete anionic metal oxide nanoclusters formed by early transition metals in their highest oxidation states (Pope and Müller, 1994). This family of compounds have been studied extensively because its chemical properties can be varied considerably due to the structure characteristics (Seaton et al., 2017; Ma et al., 2017), that makes them suitable for applications in fields like catalysis, energy, magnetism and materials science (Sécheresse, 2013).

In the catalysis field, the Keggin-type $\left[\mathrm{XM}_{12} \mathrm{O}_{40}\right] \mathrm{n}$ ( $\mathrm{X}=\mathrm{P}, \mathrm{Si}, \mathrm{Ge} ; \mathrm{M}=\mathrm{W}, \mathrm{Mo}$, etc.) structure is the most common and stable structure (Pope et al., 1983; Hill,

\footnotetext{
Corresponding author: zhujunjie1208@yahoo.co.jp
}

1998). The Keggin-type phosphotungstic acid $\mathrm{H}_{3} \mathrm{PW}_{12} \mathrm{O}_{40}$ has high levels of acidity and thermal stability, that makes it widely used as a solid catalyst in gas phase or as a homogeneous catalyst in liquid phase (Kozhevnikov, 1998; Mizuno et al., 1998).

Numerous studies have shown that the heteropoly acid could be converted into heterogeneous catalyst when it was supported on some supporters like silica, carbon and polymeric nanoparticles, and most of the heterogeneous catalysts showed better catalytic ability than heteropoly acid as a homogeneous catalyst (Huang et al., 2018; Liao et al., 2019).

$\left(\mathrm{NH}_{4}\right)_{3} \mathrm{PW}_{12} \mathrm{O}_{40}$, is an ammonium salt with micropores defined as "sponge crystal" by Inumaru (Inuumaru, 2006). $\left(\mathrm{NH}_{4}\right)_{3} \mathrm{PW}_{12} \mathrm{O}_{40}$ also shows acid catalytic activity for conversion of methanol to hydrocarbons (Hayashi and Moffat, 1983) and conversion of methylethylbenzene (McMonagle and Moffat, 1984). $\left(\mathrm{NH}_{4}\right)_{3} \mathrm{PW}_{12} \mathrm{O}_{40}$ has been prepared by neutralizing phosphotungstate acid with ammonium hydrogencarbonate, ammonium carbonate (Inuumaru, 2006), or prepared by reaction of $\mathrm{NH}_{4}^{+}$with in-site 
generated $\mathrm{PW}_{12} \mathrm{O}_{40} 0^{3-}$ in a strongly acidic solution (Sahiro et al., 2013).

In this research, a novel technique is proposed to synthesize a heteropoly acid supported composite. A complex hydrogel with catalytic properties was synthesized by mixing an anionic monomer AMPS with a heteropoly acid. The heteropoly acid particles were inserted inside the hydrogel by polymer chains and interaction forces between the anions. Thus, preventing the heteropoly acid from being lost during the catalytic reaction. Here, we present this method by reaction of $\mathrm{NH} 4+$ with in-site generated $\mathrm{PW}_{12} \mathrm{O}_{40}{ }^{3-}$ in a free radical polymerization process. The synthesized $\left(\mathrm{NH}_{4}\right)_{3} \mathrm{PW}_{12} \mathrm{O}_{40}$ particles were well kept in the hydrogel structure has been confirmed by Fourier Transform Infrared Spectroscopy (FT-IR), X-ray diffraction (XRD), Scanning Electron Microscope (SEM), Transmission Electron Microscope (TEM) and Thermogravimetric analysis (TGA).

\section{Experimental}

\subsection{Materials}

Monomer: AMPS (2-Acrylamido-2-methylpropane sulfonic acid) was obtained from Tokyo Chemical Industry Co., Ltd. Crosslinker: MBAA ( $N, N^{\prime}$-Methylenebisacrylamide) was obtained from Sigma Aldrich Co., Ltd. Initiator: $\left(\mathrm{NH}_{4}\right)_{2} \mathrm{~S}_{2} \mathrm{O}_{8}$ and Accelerator: $\mathrm{Na}_{2} \mathrm{SO}_{3}$ were obtained from Nacalai Tesque, INC. PTA $\left(\mathrm{H}_{3} \mathrm{PW}_{12} \mathrm{O}_{40}\right)$ was obtained from Nippon Inorganic Colour \& Chemical Co., Ltd. All chemicals were reagent-grade and used as supplied. Water used in all the experiments was distilled water.

\subsection{Synthesis of $\left(\mathrm{NH}_{4}\right)_{3} \mathrm{PW}_{12} \mathrm{O}_{40} /$ hydrogel composite}

All AMPS/ $\left(\mathrm{NH}_{4}\right)_{3} \mathrm{PW}_{12} \mathrm{O}_{40}$ composites were synthesized by free radical polymerization method. 0.025 mol AMPS, 0.00125 mol MBAA, $0.0005 \mathrm{~mol} \mathrm{Na}_{2} \mathrm{SO}_{3}$ and 0.0005 mol PTA were mixed together in one container, while 0.0005 mol $\left(\mathrm{NH}_{4}\right)_{2} \mathrm{~S}_{2} \mathrm{O}_{8}$ was in another container. Distilled water was added to make total solution volume $25 \mathrm{~mL}$, the consisted of $5 \mathrm{~mL}$ for the $\left(\mathrm{NH}_{4}\right)_{2} \mathrm{~S}_{2} \mathrm{O}_{8}$ solution and $20 \mathrm{~mL}$ for mixture of AMPS, MBAA, $\mathrm{Na}_{2} \mathrm{SO}_{3}$, and PTA. The obtained mixtures were homogenized and bubbled with nitrogen gas to remove dissolved oxygen for 1 hour, then poured into the polytetrafluoroethylene (PTFE) tube of $6 \mathrm{~mm}$ inner diameter. Reaction was conducted at $50^{\circ} \mathrm{C}$ for 24 hours. After composites were synthesized, they were cut into 3 $\mathrm{mm}$ segments and washed by methanol using Soxhlet extractor for 24 hours. Finally, the hydrogel composites were air dried at room temperature for 1 day then followed by further drying at $50^{\circ} \mathrm{C}$ for 1 day in a drying oven. Then, dried hydrogel composites were washed by deionized water at room temperature and dried for every 24 hours.

\subsection{Characterizations}

FT-IR spectra were recorded on an IRPrestige-21 (SHIMADZU) Fourier transform infrared spectrophotometer with $2 \mathrm{~cm}-1$ resolution.

Powder X-ray diffraction (XRD) patterns were measured with a MiniFlex600 (RIGAKU) diffractometer by using $\mathrm{Cu} \mathrm{K} \alpha$ radiation at ambient temperature. And crystallite sizes were calculated by using Scherrer's equation (1).

$$
\mathrm{d}=\frac{B \lambda}{\beta \cos \theta}
$$

Surface morphology was observed using an S-5200 (HITACHI High-Technologies) field-emission scanning electron microscopy at an acceleration voltage of $1.0 \mathrm{kV}$. The samples for the SEM analysis were dusted on adhesive conductive carbon paper attached to a brass sample mount.

High-resolution transmission electron microscopy (TEM) were obtained using a JEM-2010 (JEOL Ltd.) electron microscope operated at $200 \mathrm{kV}$ for obtaining TEM images. The samples for the TEM analysis were prepared on perforated carbon film mounted on a copper grid.

Thermogravimetric analysis (TGA) were measured by a TGA-50 (SHIMADZU) thermogravimetric analyzer. The samples (ca. $20 \mathrm{mg}$ ) were heated in a flow of air at $20 \mathrm{~K} \mathrm{~min}^{-1}$ from room temperature to $873 \mathrm{~K}$ and kept at $873 \mathrm{~K}$ for 10 mins.

\section{Result and Discussion}

\subsection{Synthesis and characterization}

The $\left(\mathrm{NH}_{4}\right)_{3} \mathrm{PW}_{12} \mathrm{O}_{40}$ was produced by reaction of $\mathrm{H}_{3} \mathrm{PW}_{12} \mathrm{O}_{40}$ and $\left(\mathrm{NH}_{4}\right)_{2} \mathrm{~S}_{2} \mathrm{O}_{8}$ during the free radical polymerization of the AMPS hydrogel.

Figure 1 shows FT-IR spectra of the hydrogel, composites and PTA.

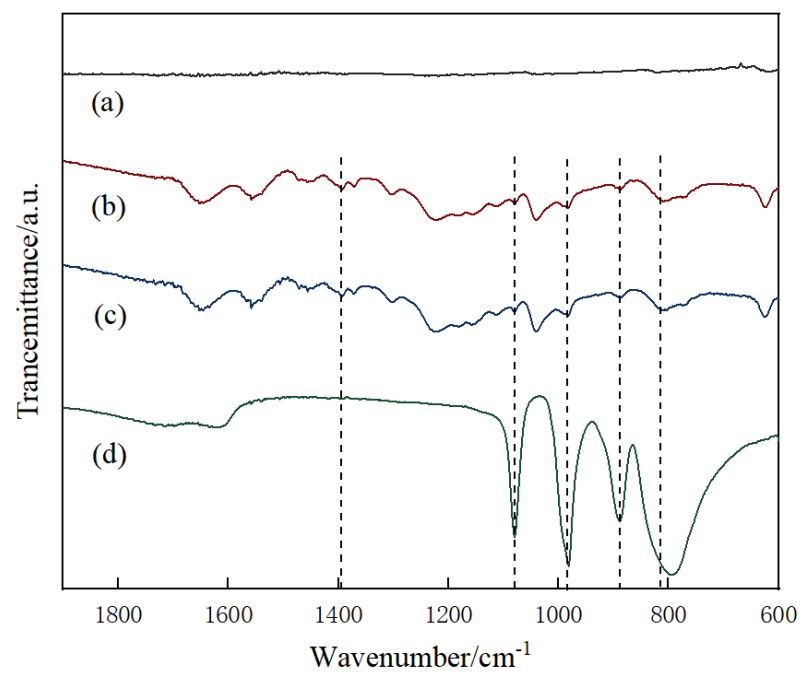

Figure 1. FT-IR spectra of sample AMPS hydrogel (a), synthesized $\left(\mathrm{NH}_{4}\right)_{3} \mathrm{PW}_{12} \mathrm{O}_{40} /$ AMPS composite (b), synthesized $\left(\mathrm{NH}_{4}\right)_{3} \mathrm{PW}_{12} \mathrm{O}_{40} /$ AMPS composite after $96 \mathrm{~h}$ washed (c), and $\mathrm{H}_{3} \mathrm{PW}_{12} \mathrm{O}_{40}(\mathrm{~d})$ 
Although the characteristic bands were much weaker than pure PTA, in both composites, characteristic bands of Keggin-type phosphotungstate $\left[\mathrm{PW}_{12} \mathrm{O}_{40}\right]^{3-}$ at 1080 , 983, 887, and $810 \mathrm{~cm}^{-1}$ could be observed, and a band corresponding to bending vibration of $\mathrm{NH}_{4}$ at $1396 \mathrm{~cm}^{-1}$ was also observed. Comparing samples (b) and (c), the positions and intensities of characteristic bands were almost the same, it showed that the $\left(\mathrm{NH}_{4}\right)_{3} \mathrm{PW}_{12} \mathrm{O}_{40}$ particles in the composite were no chemical constitution changing during the washing process. These data indicated that the $\left(\mathrm{NH}_{4}\right)_{3} \mathrm{PW}_{12} \mathrm{O}_{40}$ was contained in the composite and remained at a stable chemical state inside the composite.

Figure 2 shows XRD patterns of the AMPS hydrogel, obtained composites and PTA. XRD patterns of synthesized $\left(\mathrm{NH}_{4}\right)_{3} \mathrm{PW}_{12} \mathrm{O}_{40} /$ AMPS composite and composite after $96 \mathrm{~h}$ washed showed almost the same characteristic peaks, but different peak intensities. And both of composites had stronger peak intensities than pure PTA. In figs $2 b$ and $2 c$, the peaks at $2 \theta=22.3,27.1$, 31.3 and 36.6 were consistent with previous research (Sahiro et al., 2013). In particular, the strong peak at $2 \theta=$ 26.5 is a significant marker of $\left(\mathrm{NH}_{4}\right)_{3} \mathrm{PW}_{12} \mathrm{O}_{40}$ crystal. Crystallite sizes were calculated by using Scherrer's equation, the sizes were $8.9 \mathrm{~nm}$ (b) and $14.0 \mathrm{~nm}$ (c), respectively. It indicated that $\left(\mathrm{NH}_{4}\right)_{3} \mathrm{PW}_{12} \mathrm{O}_{40}$ nanosized crystallites were formed in the composite, however, the crystallites became larger when the washing time increased.

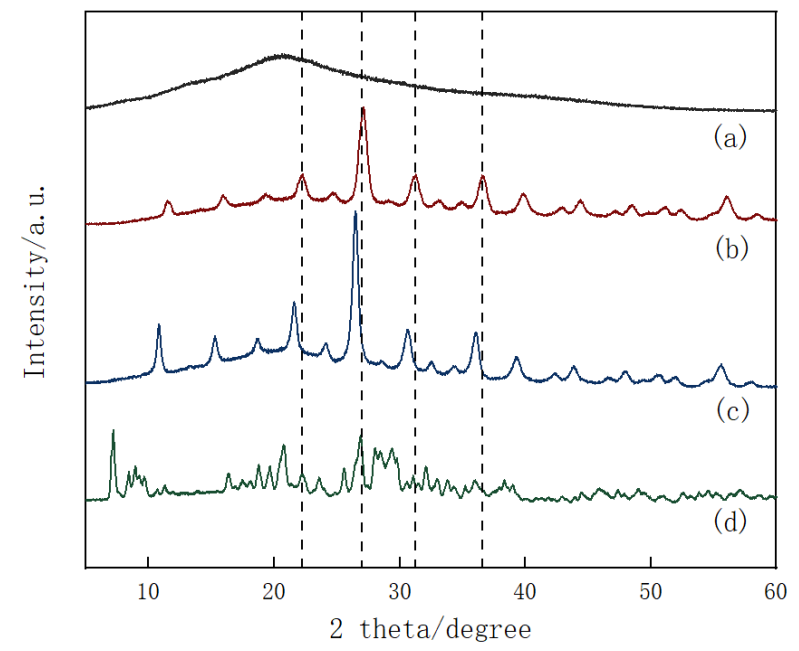

Figure 2. XRD patterns of sample AMPS hydrogel (a), synthesized $\left(\mathrm{NH}_{4}\right)_{3} \mathrm{PW}_{12} \mathrm{O}_{40} /$ AMPS composite (b), synthesized $\left(\mathrm{NH}_{4}\right)_{3} \mathrm{PW}_{12} \mathrm{O}_{40} /$ AMPS composite after $96 \mathrm{~h}$ washed (c), and $\mathrm{H}_{3} \mathrm{PW}_{12} \mathrm{O}_{40}(\mathrm{~d})$

Figure 3 shows SEM images of the AMPS hydrogel and obtained composites. Smooth surface was observed in AMPS image (a). On the other hand, a lot of small white particles were observed on the surface of the composites in (b), (c) and (d). In image (c), the higher magnification was used to observe the synthesized $\left(\mathrm{NH}_{4}\right)_{3} \mathrm{PW}_{12} \mathrm{O}_{40}$ /AMPS composite, many white particles could be clearly observed on the surface of composite. Comparing the red frame areas in (b) and (d), the white particles in (d) were more clearly observed than those in (b). It showed that these white particles in the washed composites were larger than those in the unwashed ones.

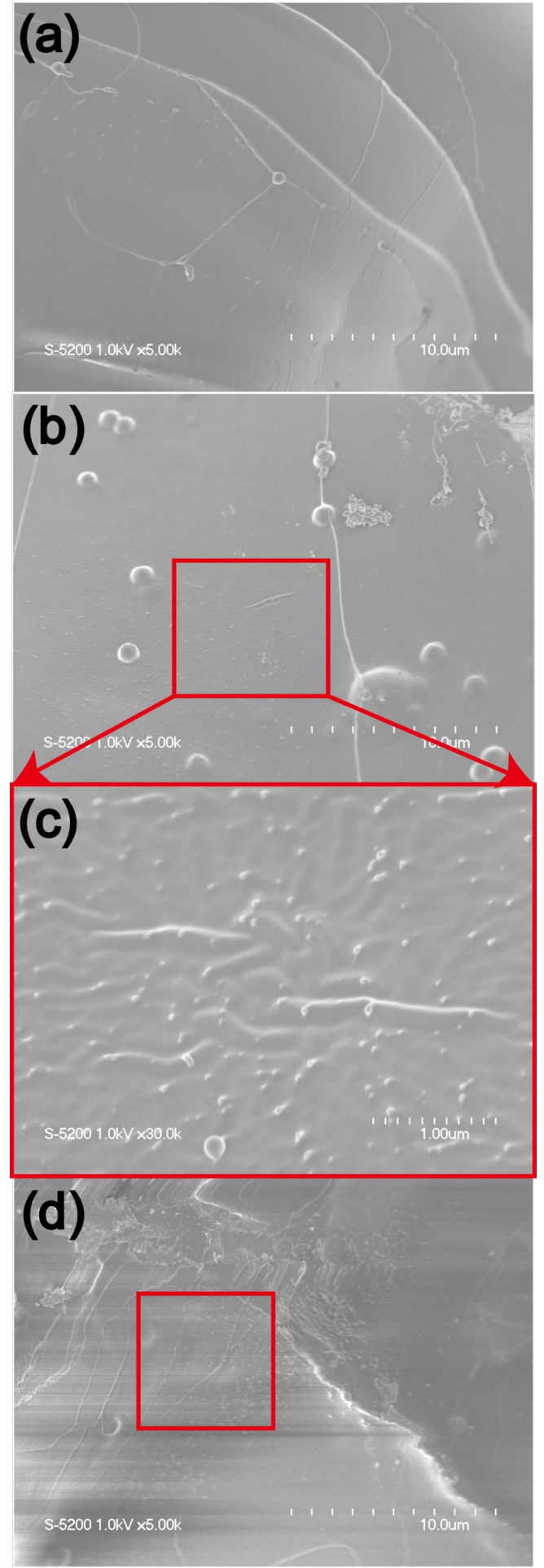

Figure 3. SEM images of sample AMPS hydrogel $\times 5.0 \mathrm{k}(\mathrm{a})$, synthesized $\left(\mathrm{NH}_{4}\right)_{3} \mathrm{PW}_{12} \mathrm{O}_{40} /$ AMPS composite $\times 5.0 \mathrm{k}$ (b), synthesized $\left(\mathrm{NH}_{4}\right)_{3} \mathrm{PW}_{12} \mathrm{O}_{40} /$ AMPS composite $\times 30.0 \mathrm{k}(\mathrm{c})$, and synthesized $\left(\mathrm{NH}_{4}\right)_{3} \mathrm{PW}_{12} \mathrm{O}_{40} / \mathrm{AMPS}$ composite after $96 \mathrm{~h}$ washed $\times 5.0 \mathrm{k}(\mathrm{d})$

This result might be caused by nanosized particle agglomeration. During the washing process, the AMPS hydrogel absorbed water and swelled, so that the polymeric structure became loose. It led to the nanosized particles agglomerating easily. These results indicate that the small particles were dispersed in the composites at first. However, with the washing time increasing, the 
particles became larger. It conjectured that these white particles were clusters which were aggregated by $\left(\mathrm{NH}_{4}\right)_{3} \mathrm{PW}_{12} \mathrm{O}_{40}$ nanosized crystallites, with the washing time increasing, the nanosized crystallites agglomerated and formed larger clusters. In order to verify this conjecture, the TEM analysis was performed.

Figure 4 shows TEM images of the obtained composite. (a) and (b) show synthesized composite in different magnifications, (c) and (d) show washed composite in different magnifications. In the TEM images, both samples showed the similar particle agglomerated states. Although the particles had an agglomerated state, primary crystallites could still be observed. It suggested that the growth of $\left(\mathrm{NH}_{4}\right)_{3} \mathrm{PW}_{12} \mathrm{O}_{40}$ nanosized crystallites was suppressed by an interaction between polymer chains and crystallites. The crystallites sizes increased slightly from $8.9 \mathrm{~nm}$ to $14.0 \mathrm{~nm}$ after 96 $\mathrm{h}$ washing. It was also proved by the results in XRD analysis as expressed in Figure 2.

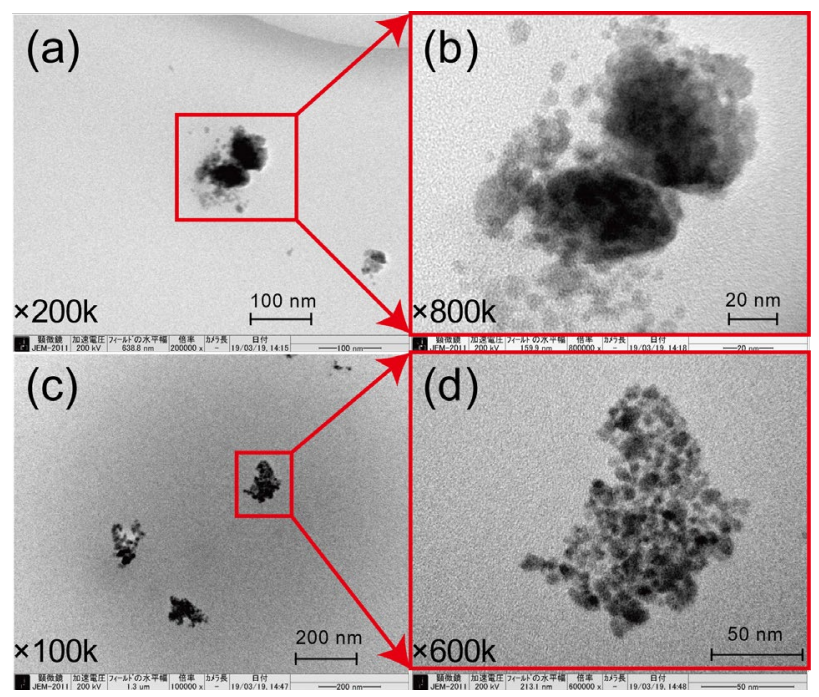

Figure 4. TEM images of sample synthesized

$\left(\mathrm{NH}_{4}\right)_{3} \mathrm{PW}_{12} \mathrm{O}_{40} /$ AMPS composite $\times 200 \mathrm{k}(\mathrm{a}), \times 800 \mathrm{k}$

(b), and synthesized $\left(\mathrm{NH}_{4}\right)_{3} \mathrm{PW}_{12} \mathrm{O}_{40} /$ AMPS composite after $96 \mathrm{~h}$ washed $\times 100 \mathrm{k}(\mathrm{c}), \times 600 \mathrm{k}(\mathrm{d})$

\subsection{Catalyst stability and recoverability}

Figure 5 shows particle contents of the composites obtained by TGA. During the washing process, the particle contents were kept at about $17 \%$, while the mass fraction of PTA in the materials solution was about $20 \%$ before preparation of the composites. It suggested that hydrogel supporter played an important role to keep particle content at a high level. In composites, the average size of clusters which were aggregated by nanosized catalyst particles was about $100 \mathrm{~nm}$, and in other researches indicated, the hydrogel network mesh size was usually smaller than $100 \mathrm{~nm}$ (Han et al., 2014; Munoz-Pinto et al., 2015). In this case, clusters couldn't escape from the composite, so the particle content could be kept at a high level. It indicated that the $\left(\mathrm{NH}_{4}\right)_{3} \mathrm{PW}_{12} \mathrm{O}_{40}$ nanosized particles could be kept in the composite during the washing process and be recovered easily.

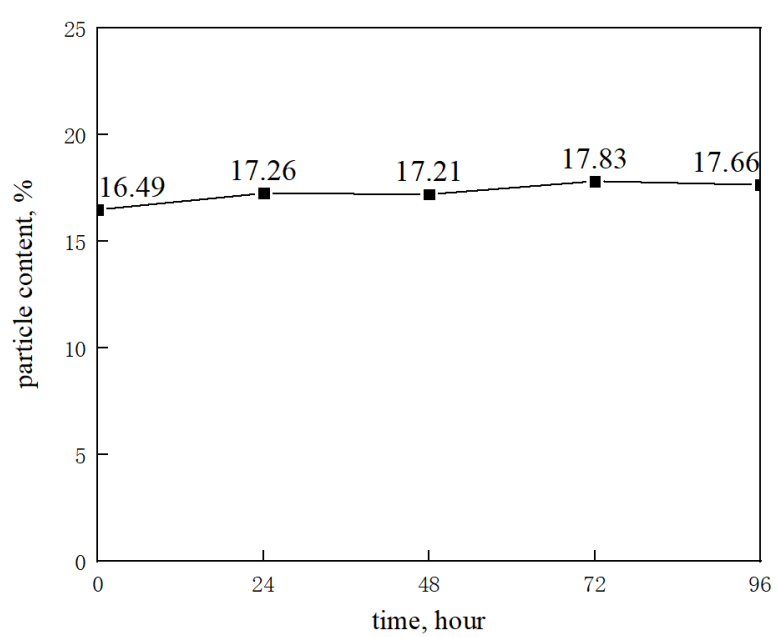

Figure 5. Particle content of synthesized $\left(\mathrm{NH}_{4}\right)_{3} \mathrm{PW}_{12} \mathrm{O}_{40} /$ AMPS composite after $0,24,48,72$, 96 washed by deionized water

\section{Conclusions}

This study presented a novel technique to synthesize a $\left(\mathrm{NH}_{4}\right)_{3} \mathrm{PW}_{12} \mathrm{O}_{40}$ nanosized particles supported composite. FT-IR and XRD experiments indicated that the $\left(\mathrm{NH}_{4}\right)_{3} \mathrm{PW}_{12} \mathrm{O}_{40}$ nanosized crystallites were formed in the composite and remained at a stable chemical state inside the composite. SEM and TEM experiments indicated that the clusters agglomerated by $\left(\mathrm{NH}_{4}\right)_{3} \mathrm{PW}_{12} \mathrm{O}_{40}$ nanosized crystallites were well dispersed in the composites, and the growth of $\left(\mathrm{NH}_{4}\right)_{3} \mathrm{PW}_{12} \mathrm{O}_{40}$ nanosized crystallites was suppressed by an interaction between polymer chains and crystallites. TG analysis indicated that the $\left(\mathrm{NH}_{4}\right)_{3} \mathrm{PW}_{12} \mathrm{O}_{40}$ particles could be kept in the composite during the washing process and be recovered easily. These results proved that the novel synthesis technique for synthesizing a heteropoly acid / hydrogel composite was feasible. In our next study, we will examine the catalytic performances of the composite in practical applications.

\section{Acknowledgements}

This research was supported by the JSPS KAKENHI Grant Number (17K06892). We are grateful to Dr. Makoto Maeda from Nature Science Centre for Basic Research and Development, Hiroshima University for his kind support in conducting SEM and TEM analysis. Mr. Syed Ragib Safi, Research fellow, Japan Society for the Promotion of Science, Hiroshima University, checked the correctness of the usage of English language in the manuscript.

\section{References}

Cavani, F., G. Centi, S. Perathoner, and F. Trifirò; Sustainable Industrial Chemistry: Principles, Tools and Industrial Examples, Wiley-VCH, Weinheim, Germany (2009) 
Clerici, M. G. and O. A. Kholdeeva; Liquid Phase Oxidation via Heterogeneous Catalysis: Organic Synthesis and Industrial Applications, Wiley, Hoboken, U.S.A. (2013)

Duprez, D. and F. Cavani; Handbook of Advanced Methods and Processes in Oxidation Catalysis, Imperial College Press, London, U.K. (2014)

Pope, M. T. and A. Müller; Polyoxometalates: from Platonic Solids to Anti-retroviral Activity, vol. 10, Springer Netherlands, Dordrecht, the Nether Land (1994)

Seaton, K., I. Little, C. Tate, R. Mohseni, M. Roginskaya, V. Povazhniy, and A. Vasiliev; "Adsorption of Cesium on Silica Gel Containing Embedded Phosphotungstic Acid," Microporous Mesoporous Mater., 244, 55-66 (2017)

Ma, T., J. Ding, R. Shao, W. Xu, and Z. Yun; "Dehydration of Glycerol to Acrolein over WellsDawson and Keggin Type Phosphotungstic Acids Supported on MCM-41 Catalysts," Chem. Eng. J., 316, 797-806 (2017)

Sécheresse, F.; Polyoxometalate Chemistry, World Scientific Publishing, Singapore (2013)

Pope, M. T.; Heteropoly and Isopoly Oxometalates, Springer-Verlag, Berlin, Germany (1983)

Hill, C.; "Introduction: Polyoxometalates-Multicomponent Molecular Vehicles to Probe Fundamental Issues and Practical Problems," Chem. Rev., 98, 1-2 (1998)

Mizuno, N. and M. Misono; "Heterogeneous Catalysis," Chem. Rev., 98, 199-217 (1998)

Kozhevnikov, I.; "Catalysis by Heteropoly Acids and Multicomponent Polyoxometalates in Liquid-Phase Reactions," Chem. Rev., 98, 171-198 (1998)

Huang, F., Y. Su, Y. Tao, W. Sun, and W. Wang; "Preparation of 5-hydroxymethylfurfural from Glucose Catalyzed by Silica-supported Phosphotungstic Acid Heterogeneous Catalyst," Fuel, 226, 417-422 (2018)

Liao, X., Y. Huang, Y. Zhou, H. Liu, Y. Cai, S. Lu, and Y. Yao; "Homogeneously Dispersed HPW/graphene for High Efficient Catalytic Oxidative Desulfurization Prepared by Electrochemical Deposition," Applied Surface Science, 484, 917-924 (2019)

Inuumaru, K.; "Sponge Crystal: a Novel Class of Microporous Single Crystals Formed by Self-assemby of Polyoxometalate $\left(\mathrm{NH}_{4}\right)_{3} \mathrm{PW}_{12} \mathrm{O}_{40} \quad$ Nanocrystallites," Catal. Surv. Asia, 10, 151-160 (2006)
Hayashi, H. and J. Moffat; "Conversion of Methanol into Hydrocarbons over Ammonium 12-tungstophosphate," J. Catal., 83 192-204 (1983)

McMonagle, J. and J. Moffat; "Pore Structures of the Monovalent Salts of the Heteropoly Compounds, 12tungstophosphoric and 12-molybdophosphoric Acid," J. Colloid Interface Sci., 101, 479-488 (1984)

Sahiro, K., Y. Ide, T. Sano, and M. Sadakane; "One-pot Synthesis of Microporous and Mesoporous $\left(\mathrm{NH}_{4}\right)_{3} \mathrm{PW}_{12} \mathrm{O}_{40}$ by Reaction of in-situ Generated $\mathrm{PW}_{12} \mathrm{O}_{40}{ }^{3-}$ with $\mathrm{NH}_{4}{ }^{+}$in a Strongly Acidic Solution," Materials Research Bulletin, 48, 4157-4162 (2013)

Munoz-Pinto, D., S. Samavedi, B. Grigoyan, and M. Hahn; "Impact of Secondary Reactive Species on the Apparent Decoupling of Poly(ethylene glycol) Diacrylate Hydrogel Average Mesh Size and Modulus," Polymer, 77, 227-238 (2015)

Han, J., J. Kim, and S. Acter; "Uniform HollowStructured Poly(vinyl amine) Hydrogel Microparticles with Controlled Mesh Property and Enhanced Cell Adhesion," Polymer, 55, 1143-1149 (2014) 